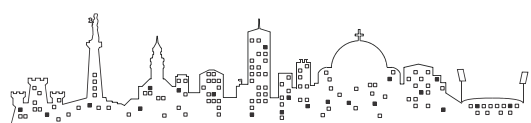

9th International Conference on Urban Drainage Modelling

\title{
Searching for storm water inflows in foul sewers using fibre-optic distributed temperature sensing
}

\author{
Rémy Schilperoort ${ }^{1}$, Holger Hoppe ${ }^{2}$, Cornelis de Haan ${ }^{1}$, Jeroen \\ Langeveld ${ }^{3,1}$ \\ ${ }^{1}$ Royal Haskoning, PO Box 151, NL-6500 AD, Nijmegen, the Netherlands, r.schilperoort@ royalhaskoning.com; \\ c.dehaan@royalhaskoning.com; j.langeveld@royalhaskoning.com \\ ${ }^{2}$ Dr. Pecher AG, Klinkerweg 5, D-40699, Erkrath, Germany, holger.hoppe @ pecher.de \\ ${ }^{3}$ Delft University of Technology, PO Box 5048, NL-2600 GA, Delft, the Netherlands, j.g.langeveld@ @udelft.nl
}

\begin{abstract}
A major drawback of separate sewer systems is the occurrence of illicit connections: unintended sewer cross-connections that connect foul water outlets from residential or industrial premises to the storm water system and/or storm water outlets to the foul sewer system. The amount of unwanted storm water in foul sewer systems can be significant resulting in a number of detrimental effects on the performance of the wastewater system. Efficient removal of storm water inflows into foul sewers requires knowledge on the exact locations of the inflows. This paper presents a monitoring technique that can be used to localize illicit storm water inflows into foul sewer systems: Distributed Temperature Sensing (DTS).

Data results from two monitoring campaigns in foul sewer systems in the Netherlands and Germany show the level of detail with which in-sewer processes can be studied. Storm water inflow can be detected as long as the temperature of this inflow differs from the in-sewer temperatures prior to the event. Also, the insewer propagation of storm water can be monitored, enabling a detailed view on advection-dispersion and mixing processes.
\end{abstract}

\section{KEYWORDS}

DTS, foul sewers, storm water inflows, temperature monitoring

\section{INTRODUCTION}

In the Netherlands, nearly $25 \%$ of all households discharge wastewater through a separate sewer system. In Germany this is the case for over $40 \%$ of households. A major drawback of separate sewer systems is the occurrence of illicit connections: unintended sewer cross-connections that connect foul water outlets from residential or industrial premises to the storm water system and/or storm water 
outlets to the foul sewer system. The majority of these connections are caused by bad plumbing during construction or renovation of a property or area. In this paper the focus is on storm water outlets connected to foul sewers.

The amount of unwanted storm water in foul sewer systems can be significant. Figure 1 presents an example for a pumping station in a foul sewer system in the Netherlands. For the considered catchment area the theoretical domestic dry weather flow adds to roughly $10 \mathrm{~m}^{3} / \mathrm{h}$, multiplying the number of inhabitants $(\approx 2000)$ with an average wastewater production of $120 \mathrm{~L} \cdot \mathrm{inh}^{-1} \cdot \mathrm{d}^{-1}$. Measured flows, however, are much larger: during dry weather the base flow varies between 20 and $50 \mathrm{~m}^{3} / \mathrm{h}$ but during storm events flows can be as large as $140 \mathrm{~m}^{3} / \mathrm{h}$. The large base flow can be attributed to continuous groundwater infiltration as well as drainage systems that discharge to the foul sewer system (which is often as intended). Flow peaks systemically coincide with storm events, leading to the conclusion that peak flows are caused by direct inflow of storm water into the foul sewer system. In this example the total pumped volume can be reduced by approximately $25 \%$ in case all direct inflows of storm water into the foul sewer system are removed.

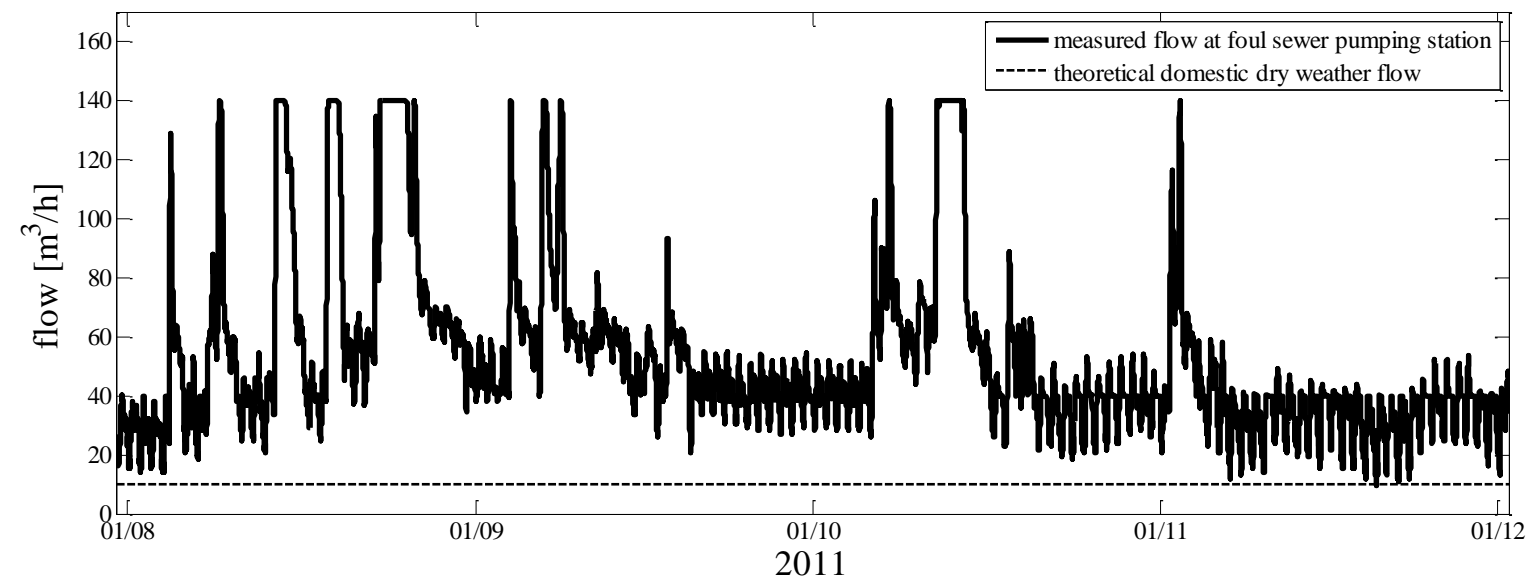

Figure 1. Measured flows at a foul sewer pumping station versus theoretical dry weather flows for a municipality in the Netherlands.

The introduction of storm water to the foul sewer system has a number of detrimental effects on the performance of the wastewater system (DWA, 2010). Foul sewer systems are not designed to handle large amounts of storm water which consequently may lead to local flooding or sanitary sewer overflows. Also, pumped volumes increase resulting in larger energy consumption. Furthermore, the dilution of wastewater with storm water has its negative effects on treatment plant capacity and efficiencies (Langeveld, 2004).

Efficient removal of storm water inflows into foul sewers requires knowledge on the locations of the inflows. A number of techniques are currently available to try to localize illicit connections such as smoke injection, sound testing and dye testing (Pitt et al., 1993). The application of these techniques can be rather labour-intensive, may require entrance onto private premises while inflows are often only detected by chance. The objective of this paper is to present an alternative monitoring technique that can be used to efficiently localize illicit storm water inflows into foul sewer systems: Distributed Temperature Sensing (DTS). The detailed monitoring results of DTS with fibre-optic cables allow quick and efficient localisation and removal of storm water inflows. In this paper the technique is explained and two examples of DTS monitoring campaigns in the Netherlands and Germany and their results are presented. 


\section{MATERIALS AND METHODS}

\subsection{Distributed Temperature Sensing}

Fiber-optic Distributed Temperature Sensing (DTS) is a widely applied technique for e.g. industrial process control, leakage detection in dams and hydrology (Johansson, 1997; Selker et al., 2006a, b). The application of fiber-optic DTS in sewer systems is performed with a standard fiber-optic cable in combination with a standalone instrument that contains a laser, sensing optoelectronics and a PC. The fiber-optic cable is laid out at the invert of a storm drain. At one end, the cable is connected to the computer/laser instrument that is generally stored outside the sewer system in a small container to protect it from weather and theft, see Figure 2.
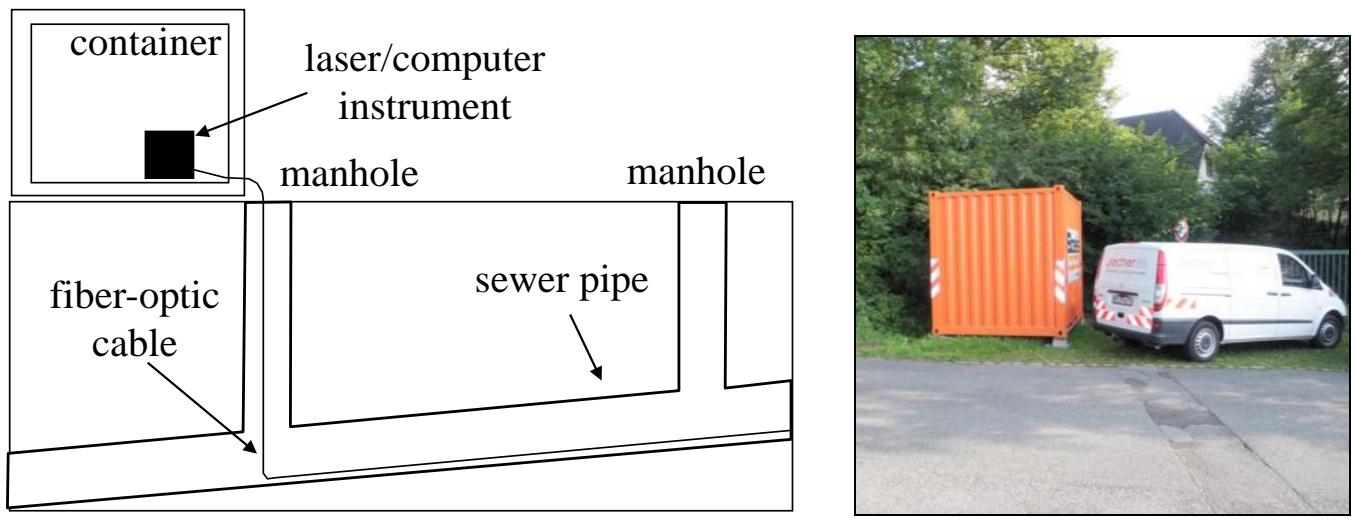

Figure 2. Standard lay-out of the DTS monitoring technique with a fibre-optic cable at the invert of a sewer pipe and the laser/computer instrument stored outside the sewer system (left) and picture of the measurement site in Wuppertal (right).

For a measurement, a continuously pulsing laser light is launched into the fibre-optic cable. At many locations along the cable each laser pulse is partially reflected by imperfections in the glass fibres. The reflected signals are 'read' by the optoelectronics and interpreted by the computer software. For each reflected signal the location of reflection can be determined using the measured travel time and known travel speed (in optic fibres typically $2 / 3$ of the speed of light in vacuum). The same reflected signal is then analysed for Raman backscattering. Raman scattering produces two broadband components at higher and lower frequencies than the main reflected signal, the so-called Stokes and anti-Stokes emissions. The ratio of the temperature-sensitive anti-Stokes intensity to the temperature-insensitive Rayleigh or Stokes intensities determines the temperature at the location of reflection (Lopez-Higuera, 2002). This way, each laser pulse yields temperature values at many locations along the fibre-optic cable. The results of all pulses emitted during a certain time-span that are reflected over a certain length along the cable are used to obtain a single temperature value for that specific time and location. Hence, results are 'averaged' over typical time and space resolutions of e.g. 1 minute and 1 meter, yielding ditto temperature data sets.

In this paper's case-studies fibre-optic cables were used carrying two glass fibres (Kaiphone Technology, Taiwan). The glass fibres (multimode 50/125 $\mu \mathrm{m}$ core/cladding diameter) are embedded in gel to avoid direct stress on the fibres, as stress can affect the reflected laser signal. The fibres are further protected by subsequent layers of PBT, stainless steel, kevlar, metal braiding and PE. The used laser/computer instrument is a HALO DTS (Sensornet, London, England). Elaborate descriptions of monitoring accuracy, temperature adaptation time of the cable, and other monitoring characteristics 
can be found in Rogers (1988), Selker et al. (2006a) and Tyler et al. (2009). Practical aspects concerning the application of DTS in sewer systems are discussed in Hoes et al. (2009). Detection limits of the technique in relation with detailed mounting of the cable in a sewer conduit are studied in Nienhuis et al. (accepted). Applications of the DTS technique in storm water sewers can be found in Hoes et al. (2009); application of the DTS technique in a combined sewer is described in Schilperoort and Clemens (2009).

\subsection{Catchment areas}

In this paper the application of the DTS monitoring technique in two different catchment areas is presented: Woensdrecht in the Netherlands and Wuppertal in Germany.

\subsubsection{Woensdrecht}

In the municipality of Woensdrecht the DTS monitoring technique has been applied in a storm water sewer as well as in the parallel foul water, see Figure 3 (left graph). The total cable length is $1500 \mathrm{~m}$, evenly divided over both sewer systems. The two fiber-optic cables have been monitored using the same computer installed in a container at the north end of the considered sewer section. A 2-week monitoring campaign (22.04.-06.05.2011) has been performed. During that time-span in-sewer temperatures have been measured with a temporal resolution of 1 minute and a spatial resolution of 2 meters.

As the area suffered from both: water quality problems (which were suspected to be related to illegal discharges of wastewater to the storm sewer) and an overloaded pumping station (storm water inflows into the foul sewer), the municipality decided to monitor both systems simultaneously. Cross referencing monitoring results from both systems helps improving diagnostics significantly.
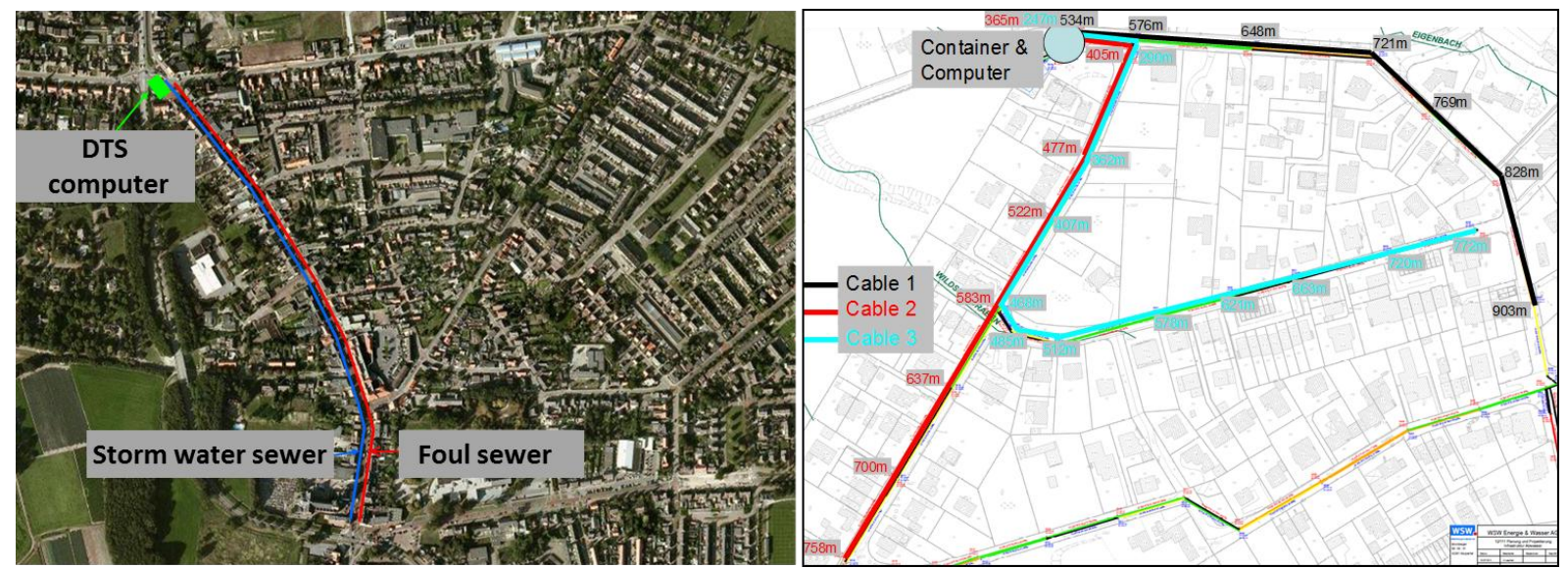

Figure 3. DTS monitoring set-up for Woensdrecht (left) and Wuppertal (right).

\subsubsection{Wuppertal}

In the framework of a city-wide project to reduce infiltration water in foul sewers carried out by the Wuppertaler Energie und Wasser AG (Hoppe et al. 2011), the catchment of an overloaded pumping station downstream a residential area was analyzed. The problem here was suspected to be associated with (large) storm water inflows, but the exact locations of the inflows were unknown. Tests with 
smoke injection and camera analysis showed no striking success. Therefore, fiber-optic cables have been installed in the complete foul sewer system with the DTS computer in a container next to the pumping station. In total, $1200 \mathrm{~m}$ of sewer system have been observed, divided over 3 sewer sections of each $400 \mathrm{~m}$, see Figure 3 (right graph). A 4-week monitoring campaign (17.08.-13.09.2011) has been performed with a temporal resolution of 1 minute and a spatial resolution of 2 meters.

\section{RESULTS AND DISCUSSION}

Figure 4 presents DTS monitoring results in the foul sewer of Woensdrecht. The horizontal axis represents length along the fiber-optic cable in the sewer system. In this case, monitoring results span from cable position $\mathrm{x}=111 \mathrm{~m}$ up to $\mathrm{x}=850 \mathrm{~m}$ as the first hundred meter of cable was not installed in the sewer system. The vertical axis represents a time-span of roughly 2 hours in April 2011. The figure consists of $375 \times 120$ pixels (respectively $750 \mathrm{~m}$ divided by a $2 \mathrm{~m}$ spatial resolution and 2 hours divided by a 1 minute temporal resolution). Each pixel presents a measured temperature value, colored according to the color bar on the right with temperatures ranging between $14^{\circ} \mathrm{C}$ and $17^{\circ} \mathrm{C}$. Flow direction in the graph is from right to left (the DTS computer is positioned at the most downstream end of the sewer section).

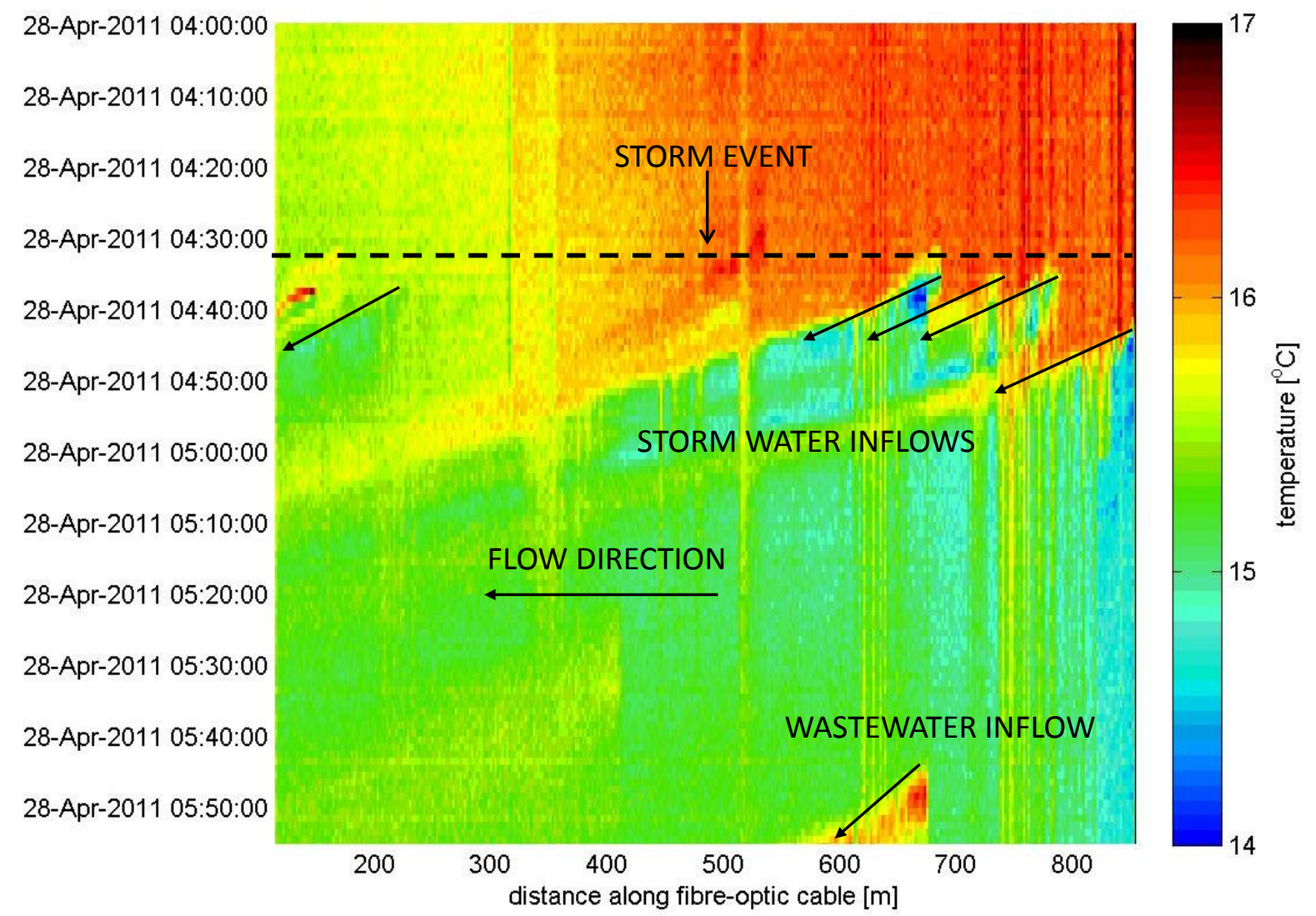

Figure 4. DTS monitoring results in a foul sewer in the municipality of Woensdrecht, the Netherlands.

Between $04 \mathrm{~h} 00$ and $04 \mathrm{~h} 30$ temperatures between $15^{\circ} \mathrm{C}$ and $17^{\circ} \mathrm{C}$ are observed. Temperatures along the upstream cable section are somewhat higher than the downstream section, but only minor temperatures variations are observed. A few minutes past $04 \mathrm{~h} 30$ a storm event occurs in the area (based on local precipitation measurements). After a few minutes sudden temperature decreases at a number of 
locations along the sewer section can be observed. At for instance cable location $\mathrm{x}=785 \mathrm{~m}$ a reduction in temperature of approximately $2^{\circ} \mathrm{C}$ can be seen. These are expected to be associated with the inflow of relatively cold storm water. From this location storm water starts flowing in a downstream direction (in the graph from right to left). At cable location $\mathrm{x}=856 \mathrm{~m}$ a more delayed reaction to the storm event can be seen: only 10 minutes after the onset of the event temperatures decrease. This is likely caused by storm water inflows further upstream the sewer section where no fiber-optic cable has been installed.

After approximately 30 minutes the inflow of storm water has cooled down the foul water system with $1^{\circ} \mathrm{C}$ to $2^{\circ} \mathrm{C}$. Around $05 \mathrm{~h} 45$ the first discharge of wastewater can be observed that is associated with a rise in temperature.

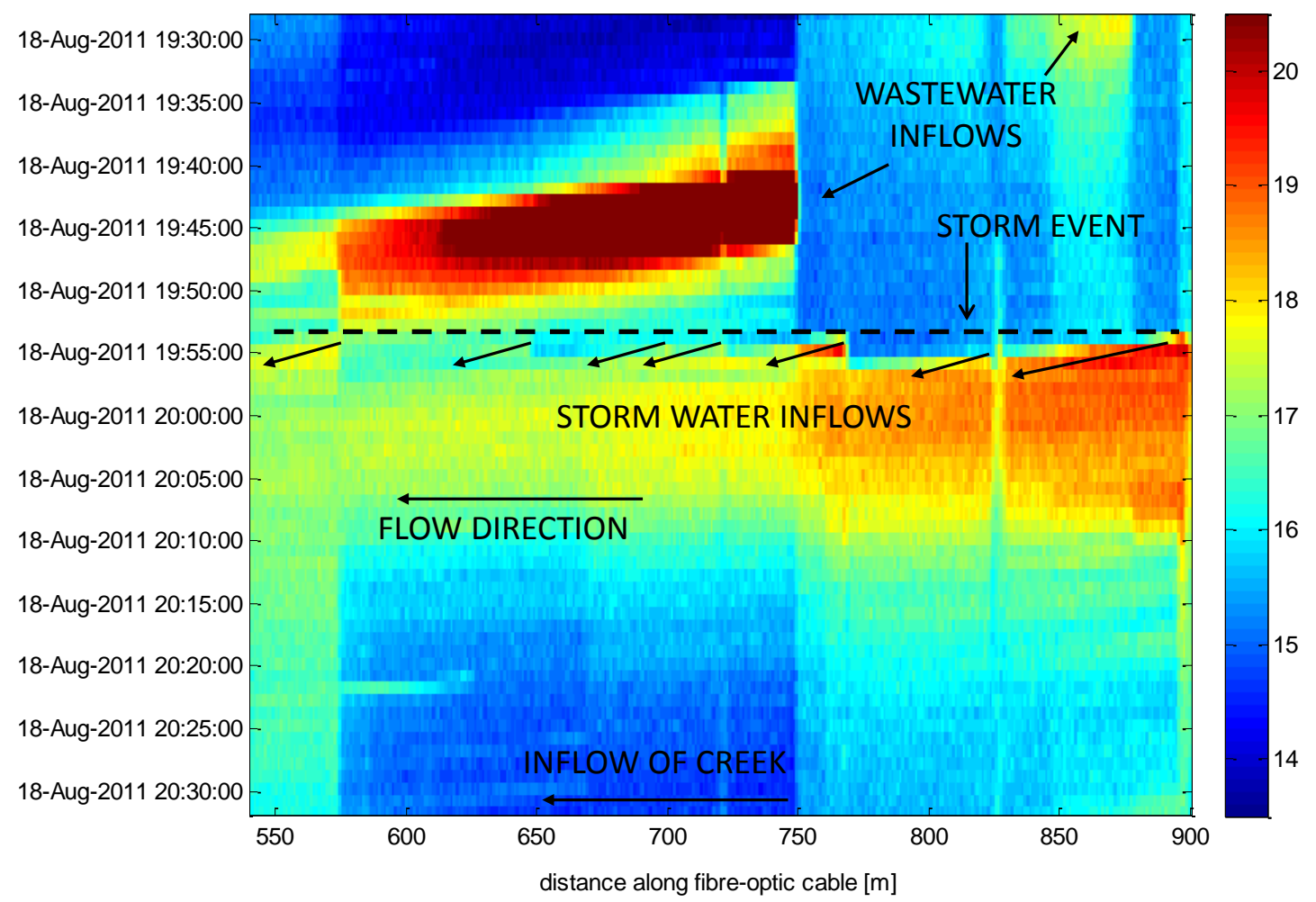

Figure 5. DTS monitoring results in a foul sewer in the municipality of Wuppertal, Germany.

Figure 5 presents DTS monitoring results of one of the three foul sewer sections in Wuppertal (cable 1, see Figure 3). Again, the horizontal axis represents length along the fiber-optic cable, in this case from cable position $\mathrm{x}=545 \mathrm{~m}$ (the location of the monitoring computer) up to $\mathrm{x}=900 \mathrm{~m}$. The vertical axis represents a time-span of roughly 1 hour in August 2011. Flow direction in the graph is again from right to left (the DTS computer is positioned at the most downstream end of the sewer, next to the pumping station).

Between $19 \mathrm{~h} 30$ and 19h50 two wastewater inflows can be observed: the remnants of a discharge prior to $19 \mathrm{~h} 30$ around cable location $\mathrm{x}=860 \mathrm{~m}$ and one large discharge at cable location $\mathrm{x}=750 \mathrm{~m}$. For the latter, the duration of the spill can be well observed as well as the transport of the 'warm water plume' through the sewer pipe. Also, the loss of energy due to the mixing with other (waste)water can be noted. 
A few minutes past $19 \mathrm{~h} 50$ a storm event occurs in the area (recorded by several local rain gauges). Analogue to the Woensdrecht case, a reaction in terms of a temperature variation can be observed in the foul sewer system. The direction of the temperature change however differs. In Woensdrecht a temperature decrease could be observed whereas the Wuppertal results show a temperature increase at various locations along the fiber-optic cable. The difference can be explained considering the meteorological conditions during the respective monitoring periods. The Woensdrecht data results have been collected in April on a normal spring day; the Wuppertal results, in contrast, have been generated in August after a relatively warm summer day. During the latter day asphalt road covers had warmed up significantly, transferring their heat to the storm water during run-off, resulting in relatively warm storm water discharges into the foul sewer system.

For the Wuppertal case it has been noted that the locations of inflowing storm water coincide with the exact locations of the manholes in the considered sewer sections. After careful considerations it has been concluded that the design of manhole covers (with a large number of ventilation openings, see Figure 6) allows storm water to enter the foul sewer system and hence contribute to the overloading of the local pumping station.

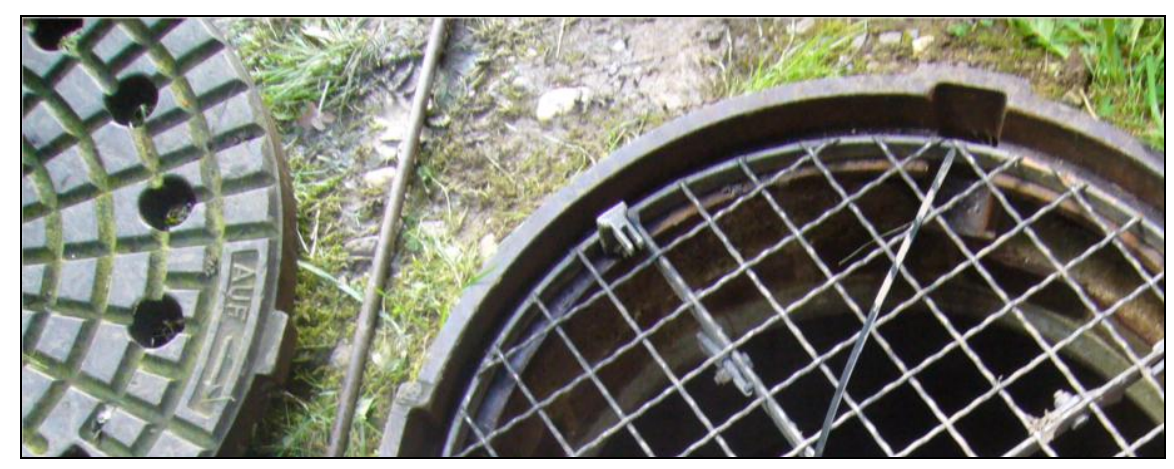

Figure 6. Manhole covers in the Wuppertal catchment area that allow storm water to enter the foul sewer system.

Another noteworthy feature of the DTS monitoring results in Wuppertal is the temperature variation at cable location $x=750 \mathrm{~m}$ at times without precipitation and/or wastewater spills. During these timespans the in-sewer temperature systematically drops a few degrees Celsius compared to the upstream sewer section. In Figure 5 this can be observed around 19h30 (prior to the large wastewater spill that coincidentally occurs at the same location) and after $20 \mathrm{~h} 20$ when the influence of the storm water on in-sewer temperatures has ceased. Data results suggest that at this location a continuous inflow of relatively cold (ground) water occurs. Visual inspection has confirmed the existence of such inflow at this location and hence another (large) contributor to the overloading of the pumping station has been identified.

\section{CONCLUSIONS}

Fiber-optic distributed temperature sensing is a powerful tool to study several in-sewer processes that influence (wastewater) temperatures. The installation of a fiber-optic cable in a foul sewer system has proven feasible. The use of a single instrument that performs the measurements and logs the data in an easy accessible and safe location and that can simultaneously monitor up to several hundreds of monitoring locations makes the DTS set-up easy to use. Moreover, the technique requires no entrance 
onto private premises which offers an advantage over other searching techniques for illicit connections.

Data from two monitoring campaigns in foul sewer systems shows the level of detail with which insewer processes can be studied. Storm water inflow can be detected as long as the temperature of this inflow differs from the in-sewer temperatures prior to the event. Temperature increases (during warm summer days) as well as the more 'standard' temperature decreases have been observed. Also, the insewer propagation of storm water can be monitored, enabling a detailed view on advection-dispersion and mixing processes.

\section{ACKNOWLEDGEMENTS}

The authors wish to acknowledge the cooperation of the municipalities of Woensdrecht and Wuppertal and the Wuppertaler Stadtwerke Energie \& Wasser AG in the presented DTS monitoring projects.

\section{REFERENCES}

DWA (2010). Fremdwasser in Entwässerungssystemen (Infiltration and inflow in drainage systems). Deutsche Vereinigung für Wasserwirtsschaft, Abwasser und Abfall e.V. (DWA), Hennef, ISBN 978-3-941897-57-1.

Hoes O.A.C., Schilperoort R.P.S., Luxemburg W.M.J., Clemens F.H.L.R. and Giesen N.C. van de (2009). Locating illicit connections in storm water sewers using fiber-optic distributed temperature sensing. Water Research, 43(20), 5187-5197.

Hoppe, H. Pecher, K.H., Laschet, U. and Gigl, T. (2011) Fremdwassersanierungskonzepte: Grundlagen - Vorgehen - Erfolgskontrolle (Remediation concepts for infiltration and inflow: principles - approach - success monitoring). Schriftenreihe zur Wasserwirtschaft, TU Graz. Aqua Urbanica 2011. Band 62, S. H1-H22. ISBN 978-3-85125-137-1.

Johansson S. (1997). Seepage monitoring in embankment dams. Ph.D. thesis, Royal Institute of Technology, Sweden.

Langeveld J.G. (2004). Interactions within the Wastewater System. PhD thesis, Technische Universiteit Delft, the Netherlands.

López-Higuera, J.M. (2002). Handbook of optical fiber sensing technology. John Wiley \& Sons Ltd, West Sussex, UK.

Nienhuis J., de Haan C., Langeveld J., Klootwijk M. and Clemens F.H.L.R. (accepted). Assessment of detection limits of fiber-optic distributed temperature sensing for detection of illicit connections. Accepted for oral presentation at 9th Int. Conf. on Urban Drainage Modeling, Belgrade, Serbia, 3-7 September 2012.

Pitt, R., Field, R., Lalor, M., Adrian, D. D. and Barbé, D. (1993). Investigation of inappropriate pollutant entries into storm drainage systems: a user's guide. Rep. No. EPA/600/R-92/238, NTIS Rep. No. PB93-131472/AS, US Environmental Protection Agency (EPA), Storm and Combined Sewer Pollution Control Program (Edison, N.J.), Risk Reduction Engrg., Lab., Cincinnati, Ohio.

Rogers A. (1988). Distributed optical-fibre sensors for the measurement of pressure, strain and temperature. Physics Reports (Review section of Physics Letters), 169(2), 99-143. 
Schilperoort R.P.S. and Clemens F.H.L.R. (2009). Fibre-optic distributed temperature sensing in combined sewer systems. Water Science and Technology, 60(5), 1127-1134.

Selker J.S., Giesen N. van de, Westhoff M., Luxemburg W. and Parlange M.B. (2006a). Fiber optics opens window on stream dynamics. Geophysical Research Letters, 33(24), art. no. L24401.

Selker J.S., Thévenaz L., Huwald H., Mallet A., Luxemburg W., Giesen N. van de, Stejskal M., Zeman J., Westhoff M. and Parlange M.B. (2006b). Distributed fiber-optic temperature sensing for hydrologic systems. Water Resources Research, 42(12), art. no. W12202.

Tyler S.W., Selker J.S., Hausner M.B., Hatch C.E., Torgersen T., Thodal C.E. and Schladow S.G. (2009). Environmental temperature sensing using Raman spectra DTS fiber-optic methods. Water Resources Research, 45, art. no. W00D23. 